\title{
ENTRE “EDUCAÇÃO ESTÉTICA” E "ESTUDOS CULTURAIS": A PROBLEMÁTICA DA PEDAGOGIA LITERÁRIA, DO PROGRAMA SCHILLERIANO AOS PCNs
}

\author{
Nabil Araújo \\ nabil.araujo@gmail.com
}

\section{SCHILLER, ARNOLD E ALÉM... ASCENSÃO DA LITERATURA COMO VALOR CULTURAL MAIOR}

“The rise of English" [A ascensão do Inglês], o célebre capítulo de Literary Theory (1983), em que Terry Eagleton reconstitui o surgimento e a consolidação da "literatura inglesa" como disciplina acadêmica e núcleo ideológico das humanidades na universidade britânica, estimula a fixação de uma versão anglocêntrica do processo de disciplinarização dos estudos literários no século XIX. Tal versão é composta, basicamente, por quatro lances:

(i) aquele que, partindo da "falência da religião" na Inglaterra vitoriana, relata a assunção da cultura literária nacional à função de amálgama social por excelência, processo que teria tido em Matthew Arnold (1822-1888) um inequívoco protagonista, o definidor de todo um programa de educação estética do povo inglês com vistas à integração ideológica entre todas as classes:

Conforme a religião progressivamente cessa de prover o "cimento" social, os valores afetivos e as mitologias básicas pelos quais uma turbulenta sociedade de classes pode ser soldada [welded together], o "Inglês" é construído como 
um sujeito para carregar esse fardo ideológico da era vitoriana para diante. A figura-chave aqui é Matthew Arnold [...]. A necessidade social urgente, como Arnold reconhece, é "helenizar" ou cultivar a classe média filistina, [...] transfundindo-lhe algo do estilo tradicional da aristocracia (EAGLETON, 1996, p. 21). A literatura treinaria as massas nos hábitos do pensamento e do sentimento pluralísticos [...]. Comunicar-lhes-ia a riqueza moral da civilização burguesa, imprimir-lhes-ia a reverência pelas realizações da classe média [...]. Dar-lhes-ia um orgulho de sua língua e literatura nacionais: se a educação escassa e extensas horas de trabalho impediam-lhes pessoalmente de produzir uma obra-prima literária, podiam ter prazer no pensamento que outros de sua própria espécie - o povo inglês - tinham produzido (Ibid., p. 22);

(ii) aquele que discrimina, na sequência, uma primeira fase da disciplinarização dos estudos de literatura nacional na Inglaterra, na qual eles ainda careceriam de dignidade acadêmica:

É significativo, então, que o "Inglês" como uma matéria acadêmica foi primeiro institucionalizado não nas Universidades, mas nos institutos de mecânica, faculdades de operários [working men's colleges] e circuitos extensivos de palestras. O Inglês era literalmente o Clássico do homem pobre - um modo de prover uma educação "liberal" barata para aqueles fora dos círculos encantados da escola pública e de Oxbridge [Oxford + Cambridge]. (Ibid., p. 23). O Inglês era um assunto arrivista, amadorístico, [...] dificilmente apto a competir em termos de igualdade com os rigores dos Grandes [história, filosofia e literatura clássicas] ou da filologia; já que, de qualquer modo, todo cavalheiro inglês lia sua própria literatura em seu tempo livre, qual era o sentido de submetê-la ao estudo sistemático? Ferozes ações de retaguarda foram travadas por ambas as antigas Universidades contra essa matéria aflitivamente diletante (Ibid., p. 25);

(iii) aquele que discrimina uma segunda e definitiva fase da disciplinarização dos estudos de literatura nacional na Inglaterra, na qual alcançam máxima dignidade acadêmica, algo motivado pela urgência nacionalista instaurada pela Primeira Guerra Mundial, da qual nem mesmo as grandes Universidades podiam escapar, assinalando-se, assim, a vitória final dos estudos ingleses em Oxford e Cambridge:

Um dos mais vigorosos antagonistas do Inglês - a filologia - estava estreitamente ligado à influência germânica; e desde que sucedia à Inglaterra estar passando por uma guerra maior com a Alemanha, foi possível depreciar a filologia clássica como uma forma de tedioso disparate teutônico em associação com a qual nenhum inglês com amor-próprio deveria ser apanhado. A vitória da Inglaterra sobre a Alemanha significou uma renovação do orgulho nacional, uma explosão de patriotismo que só podia ajudar a causa do Inglês (Ibid., p. 25-26);

(iv) aquele que reconhece ativo e, mesmo, repotencializado, em "arquitetos da nova matéria em Cambridge" como F. R. Leavis e I. A. 
Richards - principais responsáveis por tornar o "Inglês", a certa altura, "a matéria mais fundamental de todas, incomensuravelmente superior ao direito, à ciência, à política, à filosofia ou à história” (Ibid., p. 28) -, o pressupostoarnoldiano da cultura literária nacional comoamálgama social por excelência, estabelecendo-se, com isso, uma linha de continuidade ideológica ligando-os ao velho Arnold:

\begin{abstract}
Se Leavis procurou redimir a crítica convertendo-a em algo aproximado a uma religião, dando continuidade, assim, à obra de Matthew Arnold, Richards procurou, em suas obras dos anos 1920, emprestar-lhe uma base firme nos princípios de uma intransigente psicologia "científica" [segundo a qual, explica Eagleton, a religião tendo se tornado incapaz de reestabelecer o delicado equilíbrio da mente humana perigosamente perturbado pela mudança histórica e pelas descobertas científicas, essa tarefa passaria à poesia]. [...] Como Arnold, [Richards] apresenta a literatura como uma ideologia consciente para a reconstrução da ordem social, e o faz nos anos socialmente disruptivos, economicamente decadentes, politicamente instáveis que se seguiram à Grande Guerra (Ibid., p. 39).
\end{abstract}

Conceber esse processo de disciplinarização do estudo de literatura nacional nos termos de uma ruptura deliberada da Inglaterra com a Alemanha, tanto no plano político-diplomático quanto no acadêmico, na forma do repúdio à filologia clássica como ciência tipicamente germânica, enseja a sua má-compreensão como um fenômeno essencialmente inglês, justamenteporalijá-lodesuasraízes não-inglesas-ou, maisespecificamente: alemãs! Num livro publicado no mesmo ano do aparecimento da segunda edição da Literary Theory de Eagleton, o hoje célebre The university in ruins [A universidade em ruínas] (1996), Bill Readings reinsere o mesmo processo que havia sido descrito por Eagleton como "a ascensão do Inglês" num processo ainda mais amplo, ao modo, na verdade, de um segundo movimento desse processo mais amplo, o qual teria tido seu primeiro e mais decisivo movimento na Alemanha de fins do século XVIII e princípios do XIX, na esteira da revolução filosófica kantiana.

Buscando, na verdade, mapear o surgimento da ideia moderna de Universidade (com vistas a compreender sua derrocada na contemporaneidade), Readings defende que "a universidade se torna moderna quando todas as suas atividades são organizadas em vista de uma única ideia regulatória, que Kant afirma dever ser o conceito de razão", sendo que "os idealistas alemães, de Schiller a Humboldt", prossegue Readings, "atribuem um papel mais explicitamente político à estrutura determinada por Kant, e o fazem substituindo a noção de razão por aquela de cultura" (READINGS, 1996, p. 14-15); mais tarde, caberá, segundo Readings, a intelectuais ingleses como John Newman e Matthew Arnold, literaturizar, 
por assim dizer, a noção alemã de cultura, fazendo da literatura a disciplina central da Universidade. "Discutindo os exemplos de Arnold, de Leavis e dos New Critics", esclarece Readings, "traço a ligação implícita entre o modo como a 'literatura' é institucionalizada como disciplina universitária em termos explicitamente nacionais e uma visão orgânica da possibilidade de uma cultura nacional unificada" (Ibid., p. 16). Ora, o importante aqui é que essa "visão orgânica" teria surgido na Alemanha, e não na Inglaterra, justamente por obra dos filósofos idealistas que: "Com base numa aporia na filosofia kantiana”, pondera Readings, "deduziram não apenas a universidade moderna mas também a nação alemã” (Ibid., p. 62).

Como observa Readings, coube a Schiller resolver a referida aporia kantiana. Por um lado, com Kant, Schiller "reconhece a capacidade da razão para exaltar o homem ao nível do universal", pois ela "centra o sujeito como autônomo, capaz de refletir sobre um mundo de determinações do qual ele é liberto como um puro ponto de consciência" (Ibid., p. 63). Para Schiller, em suma, "o homem é de fato emancipado pela razão", pondera Readings - o problema é o preço a ser pago por essa emancipação kantianamente concebida:

Como Schiller assinala, a imposição do estado moral da razão pura só pode avançar ao custo da destruição da condição pré-existente, não-emancipada da humanidade, caracterizada pela interioridade do "sentimento natural". A antinomia entre natureza e razão em Kant não deixa escolha ao sujeito: chegar à razão é destruir a natureza, alcançar a maturidade é esquecer absolutamente a infância (Ibid., p. 63).

Esse problema é expresso por Schiller nos termos da dificuldade de “como passar do 'estado de natureza' para o 'estado de razão' sem destruir a natureza”, observa Readings, acrescentando: "A resposta, resumidamente, é: através da cultura como um processo de educação estética" (Ibid., p. 63). Isso porque se, por um lado, "a arte remove o acaso da natureza (para permitir a moralidade)", por outro, e ao mesmo tempo, "não liberta a razão inteiramente da natureza"; assim:

Esta Bildung é um processo de desenvolvimento do caráter moral que situa a beleza como um passo intermediário entre o caos da natureza e as estritas e arbitrárias estruturas da razão pura. A arte encontra-se, então, entre a determinação puramente passiva da razão pela natureza (o homem como besta) e a determinação completamente ativa da natureza pela razão (o homem como máquina) (Ibid., p. 63).

A moralidade possibilitada pela "educação estética do homem" segundo Schiller seria alcançada não, bem entendido, rejeitando-se a 
natureza, mas dela removendo o acaso, isto é, "reinterpretando[-se] a natureza como um processo histórico" - e, para tanto, conclui Readings, "a razão deve substituir a crença; o Estado deve substituir a Igreja” (Ibid., p. 63). Em outras palavras, a Bildung schilleriana só poderia ter lugar no âmbito e por intermédio do Estado racional; este, por sua vez, só por efeito da Bildung poderia consolidar-se plenamente, em sua concretude histórica de EstadoNação espiritualmente coeso - do qual o modelo supremo, para os idealistas alemães, era a Grécia clássica. "De acordo com Schiller, a modernidade substituiu uma cultura unificada por uma civilização fragmentada, que é mais variada (e em alguns sentidos mais avançada) em seus conhecimentos particulares, mas menos plena de sentido", explica Readings, acrescentando: "Através da Bildung, o Estado-Nação pode alcançar cientificamente a unidade cultural que os gregos outrora possuíram naturalmente"; e ainda: "O Estado-Nação virá a reincorporar a unidade que a multiplicação e a separação disciplinar de conhecimentos impuseram na esfera intelectual, que a divisão do trabalho impôs na esfera social" (Ibid., p. 65).

Como mediadora institucional desse processo pelo qual "o Estado racional deve educar a humanidade, mas apenas uma humanidade educada pode fundar aquele Estado" (Ibid., p. 63), surge a universidade moderna, tal como idealizada por Humboldt, e "que dá assim ao povo uma ideia do Estado-Nação ao qual corresponder, e ao Estado-Nação um povo capaz de corresponder àquela ideia" (Ibid., p. 65). E ainda:

O plano delineado por Humboldt para a Universidade de Berlim sintetizou a reorganização fundamental do discurso sobre o conhecimento pela qual a Universidade assumiu uma função indireta ou cultural para o Estado: aquela da busca simultânea pelo seu sentido cultural objetivo como uma entidade histórica e pela formação moral subjetiva de seus sujeitos como potenciais portadores dessa identidade (Ibid., p. 68).

Ora, é justamente essa dupla "função cultural" da Universidade para com o Estado, e que nas modernas universidades alemãs havia de ser prioritariamente exercida pela filosofia, aquela que, segundo Readings, passará a ser exercida, nas universidades do mundo anglófono, pela literatura, de modo que "o departamento de literatura nacional vem gradualmente a substituir o departamento de filosofia como o centro das humanidades, e, a fortiori, como o centro espiritual da Universidade" (Ibid., p. 78). Essa é, pois, a linha subterrânea de continuidade ideológica ligando decisivamente a Inglaterra de Arnold - e, consequentemente, de Leavis e Richards - à Alemanha de Schiller, linha que será reconhecida e explicitada nos seguintes termos por Terry Eagleton em The idea of culture [A ideia de cultura] (2000): 
Para o Estado florescer, ele deve inculcar em seus cidadãos os tipos apropriados de disposição espiritual; e é isso o que a ideia de cultura ou Bildung significa numa venerável tradição de Schiller a Matthew Arnold. Na sociedade civil, os indivíduos vivem num estado de antagonismo crônico, dirigidos por interesses opostos; mas o Estado é aquele domínio transcendente no qual essas divisões podem ser harmoniosamente reconciliadas. Para isso acontecer, contudo, o Estado deve já ter estado em atividade na sociedade civil, aplacando seu rancor e refinando suas sensibilidades; e esse processo é o que conhecemos como cultura. Cultura é um tipo de pedagogia ética que nos moldará para a cidadania política liberando o eu ideal ou coletivo ocultado dentro de cada um de nós, um eu que encontra representação suprema no domínio universal do Estado (Ibid., p. 6-7).

Enfatizando essa função verdadeiramente constitutiva da Bildung schilleriana para com o Estado como "presença do universal dentro do domínio particularista da sociedade civil” (Ibid., p. 8), Eagleton prossegue:

Com efeito, cultura, para Schiller, é o mesmo mecanismo daquilo que será mais tarde chamado "hegemonia", moldando sujeitos humanos às necessidades de um novo tipo de governo, remodelando-os, a partir do zero, em agentes dóceis, moderados, nobres, pacíficos, conciliadores, desinteressados daquela ordem política. Mas, para fazer isso, a cultura deve também agir como um tipo de crítica imanente ou de desconstrução, ocupando uma sociedade irregenerada a partir de dentro para demolir sua resistência aos movimentos do espírito (Ibid., p. 8).

Como Readings antes dele, também Eagleton ora destaca tanto (a) a estreita conexão entre Bildung e nacionalidade no alicerce do moderno Estado-Nação - "À medida que a nação pré-moderna dá lugar ao moderno Estado-Nação", ele diz, "a estrutura de papeis tradicionais não pode mais manter a sociedade unida, e é a cultura, no sentido de uma língua, uma herança, um sistema educacional comuns, valores compartilhados, etc., que intervém como o princípio de unidade social" (Ibid., p. 26) quanto, em contrapartida, (b) a dependência da cultura em relação ao Estado-Nação, que "não celebra incondicionalmente a ideia de cultura", sendo que "qualquer cultura nacional ou étnica particular só mostrará seu valor através do princípio unificador do Estado” (Ibid., p. 59). Eagleton ora destaca, ademais, a conversão, a certa altura, da literatura em depositário maior dos valores culturais sustentadores/sustentados do/pelo Estado-Nação: ela, a literatura, "de Arnold em diante", observa Eagleton, "herda as pesadas tarefas éticas, ideológicas e mesmo políticas que foram outrora confiadas a discursos antes mais técnicos ou práticos" (Ibid., p. 40). 
Note-se que esse mesmo processo descrito por Readings e Eagleton com vistas à Europa e aos EUA é estendido por uma Beatriz Sarlo também à América Latina:

\begin{abstract}
Durante muito tempo, pensou-se que era sobre ideias escritas em livros que podia fundamentar-se a argumentação sobre a "boa" sociedade e seu governo. Por isso, os livros, especialmente a literatura, a filosofia e a história, foram decisivos na formação dos estados modernos. Esse foi o caso de muitos países latino-americanos, nos quais a república surgiu como criação consciente de uma vontade intelectual nacional. Na Argentina, as escolas foram um eixo do programa republicanoe, em poucas décadas, incorporaramà cidadania centenas de milhares de imigrantes e nativos. Além disso, os homens da organização nacional confiaram a um livro a chave do enigma político que deviam resolver: Sarmiento acreditou que Facundo era uma das suas melhores credenciais para aspirar ao governo. A escola moderna fixou no ensino da língua, da história e da literatura nacional o trívio da educação das massas. As universidades deviam fornecer uma elite ilustrada dentro da qual seriam aceitos os melhores filhos dos mais pobres (SARLO, 2002, p. 37-38). ${ }^{1}$
\end{abstract}

${ }^{1}$ No livro que se impôs como a grande referência sobre o papel da classe letrada da América Latina no planejamento e desenvolvimento dos centros urbanos da região como núcleos de poder, La ciudad letrada [A cidade letrada] (1984), Angel Rama, depois de distinguir o Brasil como o "país cuja produção literária mais articuladamente havia contribuído para a constituição nacional” (RAMA, 1984, p. 90), afirma: "A constituição da literatura, como um discurso sobre a formação, composição e definição da nação, haveria de permitir a incorporação de múltiplos materiais alheios ao circuito anterior das belas-letras que emanavam das elites cultas, mas implicava também uma prévia homogeneização e higienização do campo, o que só podia ser realizado pela escrita. A constituição das literaturas nacionais que se cumpre em fins do século XIX é um triunfo da cidade letrada, a qual pela primeira vez, em sua longa história, começa a dominar o seu contorno. Absorve múltiplos aportes rurais, inserindo-os em seu projeto e articulando-os com outros para compor um discurso autônomo que explica a formação da nacionalidade e estabelece admiravelmente seus valores. É estritamente paralela à impetuosa produção historiográfica do período, que cumpre as mesmas funções: edifica o culto dos heróis, situando-os acima das facções políticas e tornando-os símbolos do espírito nacional; dissolve a ruptura da revolução emancipadora que haviam cultivado os neoclássicos e mesmo os românticos, recuperando a Colônia como o obscuro berço onde se havia forjado a nacionalidade (no Brasil, é a obra de Capistrano de Abreu); redescobre as contribuições populares, localistas, como formas incipientes do sentimento nacional e, timidamente, as contribuições étnicas mestiças; sobretudo, confere organicidade ao conjunto, interpretando esse desenvolvimento secular da perspectiva da maturação nacional, da ordem e progresso que leva adiante o Poder" (Ibid., p. 91-92). 


\section{DECLIINIO DOS ESTUDOS LITERÁRIOS, ASCENSÃO DOS ESTUDOS CULTURAIS}

A sucessão de verbos no passado no supracitado trecho de Sarlo, introduzido pela expressão "Durante muito tempo, pensou-se...", não deixa dúvidas quanto à percepção de que já não se pensa mais assim, de que as coisas já não funcionam mais assim, seja quanto à grande função política da cultura, seja quanto à centralidade cultural da literatura (ou da filosofia, ou da história), seja quanto ao papel reservado às universidades. Bill Readings, endossando em bloco essa percepção, faz remontar as mudanças aí em jogo a um único fenômeno contemporâneo: "The decline of the Nation-State" [O declínio do Estado-Nação], título do terceiro capítulo de The university in ruins, o qual começa pela constatação de que "quando o Estado-Nação deixa de ser a unidade elementar do capitalismo, [...] ao invés de os Estados lutarem uns com os outros por melhor exemplificar o capitalismo, o capitalismo engole a ideia de Estado-Nação" - mudança essa, lembra Readings, a que se costuma chamar globalização: "a emergência contemporânea daquelas corporações transnacionais (CTNs) que atualmente controlam mais capital do que a vasta maioria dos Estados-Nação" (READINGS, 1996, p. 44). Em vista disso, eis a tese apresentada por Readings:

uma vez que o Estado-Nação não é mais a instância primária da reprodução de capitais globais, a "cultura" - como a contraparte simbólica e política ao projeto de integração perseguido pelo Estado-Nação - perdeu seu valor. O Estado-Nação e a moderna noção de cultura surgiram juntos e estão, argumento, deixando de ser essenciais a uma economia global crescentemente transnacional (Ibid., p. 12).

Nesse contexto, a "cultura" não desaparece simplesmente: antes, "é inteiramente internalizada como um elemento dentro do fluxo do capital global" (Ibid., p. 45) - ou seja: torna-se mercadoria. Como observa, nesse sentido, Terry Eagleton: "Dificilmente há, hoje, qualquer alta cultura que não seja estreitamente enquadrada pelas prioridades capitalistas - o que significa que não há nenhum problema em encenar A tempestade, contanto que você tenha o patrocínio dos Seguros Marítimos" (EAGLETON, 2000, p. 71). Beatriz Sarlo, por sua vez, constata, nesse mesmo sentido, que:

O mercado cultural - o mercado das artes visuais e o mercado dos museus, o mercado das cidades e do turismo como objetos e práticas culturais - está crescendo; todos sabemos que uma exposição de arte bem-sucedida provoca quase tanta aglomeração como a final de um campeonato de futebol (SARLO, 2002, p. 38). 
Nesse processo, aquilo que Eagleton chama de "high culture" é assimilado mercadologicamente não mais, bem entendido, como $a$ cultura pura e simples - daí, aliás, a necessidade de se agregar um qualificativo ao termo "cultura", por mais que a expressão "alta cultura" acabe se revelando, a rigor, insustentável, ao menos sem as aspas, em função da arbitrariedade do juízo de valor por ela evidentemente implicado. "Uma vez que o molde do Estado-Nação esteja quebrado”, explica Eagleton (2000, p. 63), "tipos de política cultural que nunca se ajustaram bem a esta estrutura, e não menos as políticas sexuais, estão aptos a prosperar"; essa prosperidade terá sido de tal ordem que a palavra "cultura", desde os anos 1960, observa Eagleton (Ibid., p. 38), "girou sobre seu próprio eixo até significar quase exatamente o oposto":

Ela agora significa a afirmação de uma identidade específica - nacional, sexual, étnica, regional -, ao invés da transcendência desta. E uma vez que essas identidades todas veem a si mesmas como reprimidas, o que era outrora concebido como um domínio de consenso foi transformado num terreno de conflito. Cultura, em suma, deixou de ser parte da solução para ser parte do problema. Não é mais um meio de resolver a luta política, uma dimensão mais elevada ou mais profunda na qual podemos encontrar um ao outro puramente como seres humanos; antes, é parte do próprio léxico do conflito político ele mesmo. [...] Para as três formas de política radical que têm dominado a agenda global ao longo das últimas décadas - nacionalismo revolucionário, feminismo e luta étnica - cultura como signo, imagem, significado, valor, identidade, solidariedade e auto-expressão é a própria moeda corrente do combate político, não sua alternativa olímpica (Ibid., p. 38).

É claro que também esses discursos culturais contra-hegemônicos, por assim dizer, são passíveis de assimilação como um elemento a mais no fluxo do capital global, como lembra Eagleton ao afirmar: "A cultura de identidade, igualmente, pode ser cruzada com a cultura pós-moderna ou comercial, como no caso do consumismo gay" (Ibid., p 71). Mas o mais importante aqui é o efeito que essa proliferação de culturas várias foi capaz de gerar junto à Cultura (a oposição culturas vs. Cultura é de Eagleton), isto é, a de forçá-la a uma "autoconsciência desconfortável", já que "a civilidade trabalha melhor quando é a cor invisível da vida cotidiana, e, para ela, sentir-se forçada a objetivar a si mesma é conceder demasiado a seus críticos", arriscando-se, com isso, a "ser relativizada como apenas outra cultura" (Ibid., p. 67); e ainda: "Uma vez que são desafiados seus valores, a Cultura não pode mais ser invisível. A unidade ideal da Cultura está mais e mais em desacordo com o conflito das culturas, e não pode mais se oferecer para resolvê-lo. Daí a celebrada crise da Cultura de nosso tempo" (Ibid., p. 67). 
A essa relativização da Cultura nas culturas provocada pelo declínio do Estado-Nação - movimento pelo qual, segundo Eagleton: "O conceito de cultura ganha, assim, em especificidade, o que perde em capacidade crítica" (Ibid., p. 21) -, corresponderiam, de acordo com Readings, dois efeitos maiores na universidade contemporânea: (i) "a noção de cultura como ideia legitimadora da universidade moderna atingiu o fim de sua utilidade" (READINGS, 1996, p. 5), acarretando uma "mudança fundamental no seu [da universidade] papel social e sistemas internos, mudança que significa que a centralidade das disciplinas humanísticas tradicionais para a vida da universidade não está mais assegurada" (Ibid., p. 3); (ii): "um declínio dos estudos literários nacionais e a crescente emergência dos 'Estudos Culturais' como o modelo disciplinar mais forte das humanidades" (Ibid., p. 16).

A crise atual dos estudos literários é frequentemente epitomada na chamada "questão do cânone", que claramente ultrapassa, como tal, o domínio puramente estético. "A cultura como civilidade não é apenas uma questão estética: ela sustenta, antes, que o valor de um modo de vida total está incorporado em certos artefatos concluídos”, explica Eagleton, acrescentando: "Se o cânone importa, é porque ele é a pedra de toque da civilidade em geral, não apenas por causa de seu mérito inerente. Não é uma questão da arte usurpando a vida social, mas da arte indicando um refinamento de vida ao qual a sociedade ela mesma deveria aspirar" (Ibid., p. 64). Uma vez, entretanto, que "a ligação entre o estudo literário e a formação do cidadão modelo foi quebrada”, observa Readings (1996, p. 86), "então a literatura emerge como um campo de conhecimento entre outros. O cânone vem, então, gradualmente, a funcionar como uma delimitação arbitrária de um campo de conhecimento (um arquivo) ao invés de como o recipiente que aloja o princípio vital do espírito nacional” (Ibid., p. 86); e ainda: "A função do cânone literário requer uma religião secular da literatura. Entretanto, a chama já não arde tão brilhantemente no Santo dos Santos dessa religião: o Estado-Nação, lar da ideia de cultura nacional" (Ibid., p. 86). Daí não ser acidental, defende Readings, "que a essa altura surjam uma quantidade de movimentos transdisciplinares que colocam a questão da identidade de outra maneira", e que "assinalam o fim do reinado da cultura literária como disciplina organizadora da missão cultural da universidade" (Ibid., p. 87). Assinalar [to signal] esse fim não quereria dizer, bem entendido, ser responsável por ele, isto é, causá-lo:

A emergência de práticas críticas que questionam o estatuto do literário e dedicam atenção à cultura popular é não a causa do declínio do literário, mas seu efeito. Tais práticas tornam-se possíveis a partir do momento em que a ligação entre o Estado-Nação e seus sujeitos virtuais, a ligação que a ideia de cultura (seja filosófica ou literária) da Universidade serviu historicamente para 
forjar, não é mais o solo primário de uma subjetividade generalizada. Isto é, os Estudos Culturais surgem quando a cultura deixa de ser o princípio imanente em termos do qual o conhecimento no interior da Universidade é organizado, e torna-se, ao invés, um objeto entre outros (Ibid., p. 87).

Readings insiste, com efeito, ao longo do livro, na explicitação dessas condições paradoxais de possibilidade dos Estudos então denominados culturais: "a ascensão dos Estudos Culturais torna-se possível apenas quando a cultura é desreferencializada e deixa de ser o princípio do estudo na Universidade. Na era dos Estudos Culturais, a cultura tornase meramente um objeto entre outros com que lidar o sistema" (Ibid., p. 17-18); e ainda: "A admissão de que não há nada a ser dito sobre a cultura como tal é evidente na ascensão institucional dos Estudos Culturais nos anos 1990" (Ibid., p. 90); e ainda: "As ciências humanas podem fazer o que quiserem com a cultura, podem fazer Estudos Culturais, porque a cultura já não mais importa como uma ideia para a instituição" (Ibid., p. 91), podendo tornar-se, assim, "uma disciplina, no lugar de uma ideia metadisciplinar" (Ibid., p. 92); e ainda: "O que permite aos Estudos Culturais ocuparem o campo inteiro das humanidades sem resistência é sua própria academicização da cultura, o seu tomar a cultura como o objeto do desejo de conhecimento da Universidade ao invés de como o objeto que a Universidade produz" (Ibid., p. 99).

Este que Readings admite ser um "argumento polêmico" presta-se, segundo ele próprio, sobretudo a "criticar os esforços - por mais que bem-intencionados - de converter os Estudos Culturais na disciplina que salvará a Universidade devolvendo-lhe sua verdade perdida" (Ibid., p. 18). Sim, porque segundo Readings: "O problema dos Estudos Culturais é que tentam cumprir as pretensões redentoras da crítica cultural enquanto as estendem de modo a cobrir tudo. É por isso que as atividades em Estudos Culturais encontram seus lares disciplinares mais férteis nos departamentos expandidos de literatura nacional" (Ibid., p. 103); e ainda:

as afirmações radicais dos Estudos Culturais exibem uma continuidade bem maior do que poderia ser esperado com a pretensão redentora que sustentava o modelo literário de cultura, por mais que se oponham a suas formas institucionais. Sustento que o sucesso institucional dos Estudos Culturais nos anos 1990 é devido ao fato de que eles preservam a estrutura do argumento literário, enquanto reconhecem que a literatura já não pode mais funcionar jogando fora o bebê e mantendo a água do banho, por assim dizer. Os Estudos Culturais não propõem a cultura como ideal regulatório para a pesquisa e o ensino tanto quanto procuram preservar a estrutura de um argumento a favor da redenção através da cultura, enquanto reconhecendo a incapacidade da cultura para funcionar mais tempo conforme tal ideia (Ibid., p. 16-17). 
Ora, como diz Eagleton, o conceito de cultura, nesse contexto, perde em "capacidade crítica" [critical capacity] o que ganha em especificidade, os Estudos Culturais não podendo, portanto, cumprir as "pretensões redentoras da crítica cultural" que, segundo Readings, preservam do modelo literário de cultura a que se opõem institucionalmente. "Os estudos culturais caracterizam-se pela sua perspectiva ultra-relativista”, pondera, por sua vez, Beatriz Sarlo, lembrando, assim, que eles "não são uma solução à questão da arte e da literatura, mas uma formulação dos seus problemas"; para Sarlo, em suma:

A experiência estética e a discussão dos valores estéticos podem estar baseadas numa diversidade democrática, mas requerem muito mais do que o respeito por essa diversidade. Requerem a avaliação que, no caso da arte, não vem de regras democráticas e pode não ter a diversidade como elemento norteador (SARLO, 2002, p. 39).

\section{RECALCITRÂNCIA DA “IDEOLOGIA ESTÉTICA” EM MEIO À "CRISE DA CULTURA"}

Se não exatamente da democracia e da diversidade, de onde, então, viriam as "regras" e o "elemento norteador" para a avaliação estética na era da mercantilização globalizada dos bens simbólicos? "A arte não duplica o que flui da indústria cultural, mas mantém aberto um espaço ameaçado pela indústria cultural e o mercado", pondera Sarlo, e sentencia:

\footnotetext{
A única coisa que o mercado adora fazer com a arte é vendê-la ou articulá-la em grandes exibições urbano-turísticas. O desafio está na capacidade desta de preservação de seu potencial crítico, que envolve a capacidade de estabelecer um diálogo que ilumine conflitos morais, sociais, políticos e estéticos (Ibid., p. 54).
}

Como exemplo literário privilegiado desse potencial crítico, dessa capacidade dialógico-iluminadora da arte aquém de toda apropriação mercadológica, Sarlo evoca a obra de W. G. Sebald: "Em seus livros", ela diz, "a sombra do Holocausto paira como um fundo não imediatamente visível, mas que, de toda maneira, tem distorcido o destino das suas personagens. O Holocausto é uma presença indelével e, ao mesmo tempo, silenciosa"; em suma: "A arte pode assim apresentar conflitos tão fugidios (entre o saber e o não saber) que escapam a outros discursos" (Ibid., p. 54); noutro ponto: "Quem for ler as páginas escritas por Sebald sobre a morte de um bosque familiar, poderá perceber como a literatura está afastada do romantismo ecológico (um grande relato) e, ao mesmo tempo, de que modo ela pode se fazer portadora de seus temas"; em suma: "O pathos 
e a melancolia da prosa de Sebald possuem uma forma estética que lhe permite superar todos os lugares comuns do grande relato catastrofista e, simultaneamente, indicar a catástrofe" (Ibid., p. 51).

Se essa capacidade de indicar sem explicitar, produzindo "uma presença indelével e, ao mesmo tempo, silenciosa”, pareceria, mesmo, a Sarlo, exclusiva da arte e da literatura - já que os conflitos entre o saber e o não saber aí apresentados seriam "tão fugidios" a ponto de escapar a outros discursos -, ela não seria obrigatória à arte e à literatura: "A literatura e a arte não têm de cumprir nem essa nem nenhuma outra meta", afirma, com efeito, Sarlo, para retrucar, não obstante, na sequência: "Contudo, elas já comprovaram que podem trabalhar sobre problemas comuns, sonhos, mitos, medos, utopias, fragmentos de história" (Ibid., p. 51).

Problemas comuns a quem? - poder-se-ia perguntar. Sonhos, mitos, medos, utopias de quem, ou para quem? Fragmentos de qual história? Sarlo não responde. Mas o fato de que ela se permita epitomar essas esferas assim intransitivamente concebidas seja no Holocausto, seja na problemática ecológica tal como avultados na obra de um escritor academicamente cultuado como Sebald, e não, por exemplo, no que ela chama de "derivados artísticos em campos importantes da vida cotidiana, na publicidade ou na MTV" (Ibid., p. 38) evidencia sua inclinação a contrapor algo como a "verdadeira" arte/ cultura, expressão genuína de uma coletividade universal profunda (de seus problemas, sonhos, mitos, medos, etc.), a uma arte/ cultura inautêntica à medida que mero produto da "indústria cultural" irrefletidamente consumido pelas massas. $\mathrm{O}$ grande problema quanto a isso é que, como alerta Readings (1996, p. 50-51), "já não podemos mais opor uma 'cultura' autêntica, ideal, ou nacional ao capitalismo, como se a cultura fosse o verdadeiro modo dos processos sociais e o capitalismo uma cultura falsa ou uma anticultura"; Readings prossegue:

\footnotetext{
Nos anos 1980 a esquerda britânica procurou atacar o thatcherismo como uma traição a uma verdadeira cultura nacional, um falso nacionalismo que servia aos interesses do capital global. Estavam condenados ao fracasso desde o começo, pois não compreenderam que o apelo do nacionalismo thatcherista, aquilo que lhe permitia servir às CTNs [corporações transnacionais], era precisamente que se tratava de um nacionalismo contra a ideia modernista de Estado-Nação. Essa contradição interna ao nacionalismo thatcherista era a raiz tanto de seu apelo quanto de sua flexibilidade, de modo que expor a contradição não bastava para vencer o argumento. Fusão global e fissão nacional vão de mãos dadas e trabalham juntas para apagar a ligação entre o Estado-Nação e vida simbólica que desde o século XVIII tem constituído a ideia de "cultura nacional". Nesta situação, recorrer a uma noção de cultura universal ou global é desconhecer que tais recursos sempre modelam o universal ou o global de acordo com os contornos do moderno Estado-Nação europeu, a própria instância que está sendo pulverizada pelas CTNs (Ibid., p. 51).
} 
Seria preciso, em outras palavras, reconhecermos definitivamente que "o terreno no qual costumávamos fazer amplas reivindicações para as humanidades foi minado", alerta Readings, sob pena de terminarmos como os britânicos, "que não puderam resistir aos cortes thatcheristas porque não puderam encontrar argumento melhor para as humanidades do que vagos apelos à 'riqueza humana' num mundo em que o lazer já se tornou o espaço primário de penetração capitalista" (Ibid., p. 9o). Uma consciência apurada desse estado de coisas levará mesmo o esquerdista britânico Eagleton a concluir: "Não pode mais haver, em suma, aquele sonho de identidade entre o racional e o afetivo, o cívico e o cultural, que o hífen em 'EstadoNação' procurou assegurar" (EAGLETON, 2000, p. 80).

É exatamente esse sonho, contudo, aquele que parece ainda intimamente sonhado pela esquerdista argentina Sarlo, por mais que ela explicitamente se afaste de um comprometimento estrito com o ideal identitário clássico do Estado-Nação, com o modelo de sociedade orgânica por ele professado: "Se considerarmos a sociedade, não como uma síntese de interesses que seriam combinados num hipotético fim da história, mas como uma trama de conflitos cuja resolução dá origem a novos conflitos", afirma Sarlo (2002, p. 54), "há um espaço para o pensamento crítico e para arte como discursos que nos obrigam a depararmo-nos com o incompleto, a morte e a não-reconciliação ou plenitude". Mas, concebida a sociedade não mais como "síntese de interesses" e sim como "trama de conflitos", o que é que permitiria, ainda, como o faz Sarlo, falar num "nós", postular discursos que "nos obrigam" a "depararmo-nos" com o que quer que seja? Fora da tutela do Estado-Nação e da "cultura nacional", qual seria a cola, o amálgama, afinal, a possibilitar o vínculo identitário pressuposto por esse grande "nós" com que Sarlo se permite ainda sonhar quando fala da função da arte e da literatura?

Coube a Alberto Moreiras o mérito de reconhecer o que distingue, a princípio, Beatriz Sarlo daqueles entre seus pares latino-americanistas hispanófonos adeptos do que John Beverly, numa referência ao célebre Ariel (1900) de José Enrique Rodó, denominou "neo-arielismo": se, no começo do século passado, Rodó defendeu em seu texto "a espiritualidade de uma certa 'latinidade', cuja guarda era confiada à 'juventude' intelectual latino-americana como a única real defesa contra a invasão do imperialismo norte-americano" (MOREIRAS, 2001, p. 246), os neoarielistas contemporâneos - Moreiras destaca os nomes de Hugo Achugar e Mabel Moraña - procuram, por sua vez, "posicionar novamente a literatura e os intelectuais literários - agora, entretanto, no modo da ideia de Angel Rama de uma cultura literária modernista de esquerda - como os portadores da originalidade e possibilidade culturais da América Latina" (John Beverly apud MOREIRAS, 2001, p. 246). Isso posto: 
Pareceria como se o impulso principal da contribuição de Sarlo a esse complexo debate fosse libertar-se de qualquer reducionismo sócio-político em nome de uma dupla vindicação: uma vindicação do valor artístico, de um lado, e, de outro, uma vindicação da necessidade de recuperar o pensamento do valor a serviço de um projeto cosmopolita de construção da nação que recusaria todos os essencialismos da variedade identitária. O ataque de Sarlo ao que ela chama de estudos culturais depende de um recurso à noção de pensamento crítico que faz do valor estético seu fundamento próprio (Ibid., p. 246-247). ${ }^{2}$

Definindo "culturalismo" como a invocação de um "construtivismo racional a serviço de projetos sociais singularizados empreendidos sob a bandeira da identidade cultural" (Ibid., p. 303), Moreiras propõe distinguir, então, entre o "culturalismo culturalista", isto é, "um culturalismo decidido a preservar o particular local", e o "culturalismo anticulturalista", ou seja, "um tipo universalista de culturalismo, que reivindica uma genealogia iluminista europeia” (Ibid., p. 256-257). Assim: "O culturalismo de Sarlo equivale a um historicismo da variedade iluminista, no qual a estética vem a ocupar o terreno que um culturalismo propriamente culturalista teria designado à identidade cultural em algum sentido coletivo" (Ibid., p. 260). De fato, o posicionamento de Sarlo acerca da função a ser (ainda) exercida pela arte literária na esfera pública revela-se muito distante de qualquer defesa da especificidade cultural da "Nuestra América" (Martí) contra alguma ameaça imperialista estrangeira, aproximando-se, antes, sobremaneira, das defesas universalistas da literatura - contra, digamos, sua desvalorização pós-moderna - recentemente surgidas na França, como La littérature en péril [A literatura em perigo], de Tzvetan Todorov, e La littérature, pour quoi faire? [Literatura, para quê?], de Antoine Compagnon (publicadas originalmente em 2007, surgem, ambas, em edição brasileira, dois anos mais tarde).

Moreiras (2001, p. 259) observa, em síntese, que, para Sarlo, "os valores associados à produção simbólica, isto é, à interpretação do mundo, só podem ser baseados no valor estético. $\mathrm{O}$ valor estético seria o princípio geral que poderia dar valor ao valor: o fundamento do valor". Daí se depreenderia uma compactuação com aquela "ideologia estética" que, segundo Moreiras (Ibid., p. 249), "é em última análise fundada num (não importa quão residual) populismo historicista”, e que, de acordo com Paul de Man, citado por Moreiras, tem sua matriz em Schiller:

${ }^{2}$ Moreiras tem aí em vista sobretudo um texto de Sarlo publicado em periódico em 1997, intitulado "Los estudios culturales y la crítica literaria en la encrucijada valorativa", cujo espírito se mantém, poder-se-ia dizer, no aqui citado "A literatura na esfera pública". 
De um texto como as Cartas sobre a educação estética de Schiller, ou dos outros textos de Schiller que se relacionam diretamente com Kant, toda uma tradição na Alemanha [...] e em outros lugares nasceu: um modo de enfatizar, de revalorizar o estético, um modo de estabelecer o estético como exemplar, como uma categoria exemplar, como uma categoria unificadora, como um modelo para a educação, como um modelo até para o Estado (DE MAN apud MOREIRAS, 2001, p. 249).

Moreiras identifica, assim, no tipo de crítica desferida aos Estudos Culturais por alguém como Sarlo, "um tomar-por-garantida a estética schilleriana como a única estética possível (e definitivamente como um modelo para o Estado)" (Ibid., p. 249); sobre o "populismo historicista" necessariamente implicado pelo tipo de ideologia estética professada por Sarlo, ele explica:

Por historicismo populista, então, quero dizer um modo de pensar baseado horizontalmente na postulação de valores comunitários, na compreensão de que tais valores comunitários podem e devem incorporar uma universalidade comum que seria então a base para um apreender e suturar o social por parte de uma dada formação de classe ou de interclasse, cuja estratégia é fazer de si mesma o suporte para o todo social. (Ibid., p. 250).

Moreiras acrescenta que: "Esse é um modo de pensamento mais adequado para, e codeterminante de, uma forma de Estado nacionalpopular" (Ibid., p. 250), concluindo, mais à frente, que "se há alguma realidade por trás de toda a conversa sobre o relativo enfraquecimento do Estado-Nação e o desaparecimento do Estado nacional-popular e sua substituição por um regime transnacional de capital, então as condições para o pensamento mudaram" (Ibid. p. 252), e é dessa falta de fundamento para os valores, da inexistência, em suma, de um valor do valor e da possibilidade ou não de um pensamento sem fundamento que seria preciso agora se ocupar:

Se os valores são o fundamento do pensamento, ou a razão da razão, como a tradição metafísica nos ensina, como se poderia imaginar então um pensamento sem fundamento [a thinking without ground] que não desvanecesse rapidamente na utopia de um pensamento sem fundamento [a groundless thinking]? Em outras palavras, como pode ser possível pensar sem um fundamento? Em teoria política e teoria da arte? Em Estudos Culturais? Esta é a questão propriamente perguntada toda vez que se ouve falar de essencialismo ou antiessencialismo, incluindo essencialismo estratégico. Concordo com Sarlo que o tipo de pensamento acadêmico que veio a ser internacionalmente identificado como Estudos Culturais talvez ainda não tenha produzido uma resposta satisfatória a essa questão, embora a necessidade disso tenha sido repetidamente anunciada. A questão não é se os Estudos Culturais [...] 
chegaram a uma resposta apropriada, pois respostas nesse nível não podem realmente ser improvisadas. [...] A questão é, antes, se os Estudos Culturais podem se abrir, de algum modo radical, para esse tipo de questionamento. Se puderem, então a condenação dos Estudos Culturais do ponto de vista de um retorno necessário a um pensamento de valores - sejam eles locais, nacionais, continentais, universais ou estéticos (o qual pode abarcar todos eles) - que sustentaria sozinho a possibilidade de pensamento crítico pareceria ser não simplesmente redutora ou superficial, mas mal orientada nas suas próprias pressuposições (Ibid., p. 254-255).

Ora, invertendo-se, então, o argumento de Moreiras: se um "pensamento de valores" [a thinking of values], mais especificamente um pensamento fundamentado no valor estético, ainda se afigura sustentável - nem redutor nem superficial nem mal orientado - para uma intelectual e acadêmica como Beatriz Sarlo - mas não só, também para um Todorov, um Compagnon, e tantos outros intelectuais e acadêmicos no nosso tempo - seria porque os Estudos Culturais não foram, de fato, até agora, verdadeiramente capazes da abertura radical para o "pensamento sem fundamento" de que fala Moreiras, e provavelmente nunca o serão, dado que a possibilidade de uma tal abertura pareceria mesmo inversamente proporcional à tão bem diagnosticada por Readings institucionalização/ disciplinarização da produção de discursos em Estudos Culturais desde o começo dos anos 1990. Tal produção discursiva de fato tem implicado uma "articulação crítica de pensamento", como quer Moreiras (Ibid., p. 256), "que pensa sobre a função ideológica através dos apelos sempre essencialistas ao valor como fundamento ou sutura", sendo que o destaque dado aí ao pensar sobre é do próprio Moreiras; ora, um pensamento sobre a falta de fundamento - isto é, que tematiza a falta de fundamento - não se converte, automaticamente, ipso facto, em pensamento sem fundamento, muito pelo contrário: o hiato entre a constatação da falta - o "thinking about" - e a performance dessa falta - o "thinking-without-ground" - pareceria mesmo intransponível. Formulação dos problemas da arte e da literatura, dir-se-ia, em suma, com Sarlo, os Estudos Culturais definitivamente "não são uma solução à questão da arte e da literatura”, não proporcionam, para além da tematização crítica do valor estético como pretenso fundamento, nada que se assemelhe ao pensar-sem-fundamento "em teoria da arte" sonhado por Moreiras. 


\section{VALOR ESTÉTICO E PEDAGOGIA LITERÁRIA NOS PARÂMETROS CURRICULARES NACIONAIS}

Não estranha, assim, e apesar da já ampla penetração do discurso produzido em Estudos Culturais no debate educacional no Brasil, ${ }^{3}$ a recalcitrância da "ideologia estética" em nossos programas escolares de ensino literário, e isso desde os próprios Parâmetros Curriculares Nacionais (PCNs) que balizam os ensinos fundamental e médio em todo o país. Quanto ao que é curricularmente previsto para cada um desses dois níveis de ensino nos PCNs, há, na verdade, uma diferença importante no modo de se postular a natureza e a função do ensino literário, diferença bastante sintomática do estado de coisas de que aqui se trata.

No que se refere ao ensino fundamental, à medida que a literatura é aí concebida em subordinação total à língua, o ensino da primeira se vê totalmente justificado no âmbito do ensino da segunda, nos termos do "reconhecimento" de uma modalidade de escrita: "A questão do ensino da literatura ou da leitura literária envolve, portanto, esse exercício de reconhecimento das singularidades e das propriedades compositivas que matizam um tipo particular de escrita" (BRASIL, 1997, p. 30), ou ainda, de modo mais amplo, de uma modalidade de uso linguístico não restrita à escrita: "O tratamento do texto literário oral ou escrito envolve o exercício de reconhecimento de singularidades e propriedades que matizam um tipo particular de uso da linguagem" (BRASIL, 1998, p. 27). Contida, assim, a microproblemática literária numa macroproblemática linguística, e se faz possível descartar como "equívoco" a identificação do literário ao moral, típica da "ideologia estética":

É possível afastar uma série de equívocos que costumam estar presentes na escola em relação aos textos literários, ou seja, tomá-los como pretexto de questões outras (valores morais, tópicos gramaticais), que não aquelas que contribuem para a formação de leitores capazes de reconhecer as sutilezas, as particularidades, os sentidos, a extensão e a profundidade das construções literárias (Ibid., p. 27).

${ }^{3}$ Rosa Maria Hessel Silveira, na apresentação ao livro por ela organizado em meados da última década, Cultura, poder e educação: um debate sobre estudos culturais em educação (2005), afirma, logo de partida: "Não se passaram ainda dez anos desde a entrada dos Estudos Culturais no âmbito da teorização e das práticas de educação no Brasil e, no entanto, eles já suscitaram 'adesões', embates, desconfianças ou entusiasmos de tal forma expressivos, que já não podem ser simplesmente ignorados. Em especial, nos últimos cinco anos multiplicaram-se os trabalhos acadêmicos e as práticas educativas que se declaram filiadas ao campo ou produzidas sob o influxo de alguns de seus conceitos mais correntes; de certa forma, a expressão Estudos Culturais pareceu se transformar em uma etiqueta mágica a sinalizar a 'atualidade' - atraindo, por vezes, paixões opostas - nos documentos, nos textos, nos trabalhos de eventos e nos currículos" (SILVEIRA, 2005, p. 5). 
Note-se que na passagem dos parâmetros voltados para o intervalo $1^{\underline{a}}$ a $4^{\underline{\underline{a}}}$ séries do ensino fundamental àqueles voltados para o intervalo $5^{\underline{a}}$ a $8^{\underline{a}}$ séries do ensino fundamental, apesar da manutenção das linhas gerais concernentes ao ensino literário, passa a figurar entre os "Valores e atitudes subjacentes às práticas de linguagem" o seguinte item: "Interesse pela literatura, considerando-a forma de expressão da cultura de um povo" (Ibid., p. 64). Isso poderia ser entendido como uma preparação do aluno das últimas séries do ensino fundamental para seu ingresso no ensino médio, no qual, como se sabe, o estudo literário se transforma, basicamente, em estudo da "literatura brasileira", abordada, via de regra, numa perspectiva histórica, de modo a autonomizar o literário em face do linguístico.

Os parâmetros curriculares voltados para o ensino médio começam justamente questionando essa dicotomização em "Língua e Literatura (com ênfase na literatura brasileira)” (BRASIL, 2000, p. 16), bem como o direcionamento do "foco da compreensão de texto" para a história da literatura (Ibid., p. 16), determinando, ao invés, um "processo de ensino/ aprendizagem de Língua Portuguesa [que] deve basear-se em propostas interativas língua/linguagem", que "destaca a natureza social e interativa da linguagem, em contraposição às concepções tradicionais, deslocadas do uso social", e no qual, por isso mesmo, a história literária se vê "deslocada para um segundo plano" e "a literatura integra-se à área de leitura” (Ibid., p. 18). Mas o que se esperaria, enfim, do ensino literário, com tais mudanças?

$\mathrm{Na}$ especificação das "Competências e habilidades a serem desenvolvidas em Língua Portuguesa” à luz do novo modelo, no quesito em que se enquadra o estudo da literatura ("Investigação e compreensão"), lê-se o seguinte: "Recuperar, pelo estudo do texto literário, as formas instituídas pelo imaginário coletivo, o patrimônio representativo da cultura e as classificações preservadas e divulgadas, no eixo temporal e espacial" (Ibid., p. 24). Nas "Orientações educacionais complementares aos Parâmetros Curriculares Nacionais" (PCN+Ensino Médio), surgidas dois anos mais tarde, a determinação dessa "competência geral" é repetida ipsis literis (BRASIL, 2002, p. 74); como "competência específica” a ela associada é acrescentado: "Resgatar usos literários das tradições populares", objetivo então subordinado à seguinte "unidade temática": "Identidade nacional" (Ibid., p. 74).

Ademais, determina-se, aí, que a leitura literária pode fazer "muito mais sentido para os estudantes" quando "passa a ser entendida não como mero exercício de erudição e estilo, mas como caminho para se alcançar, por meio da fruição, a representação simbólica das experiências humanas" (Ibid., p. 58). Essa determinação é claramente atravessada por 
dois conceitos-guia aí endossados e professados: o de (a) "cultura”, que "abarca toda manifestação que emana das trocas sociais e é transmitida através das gerações", sendo que: "A língua, bem cultural e patrimônio coletivo, reflete a visão de mundo de seus falantes e possibilita que as trocas sociais sejam significadas e ressignificadas. No domínio desse conceito está, por exemplo, o estudo da história da literatura" (Ibid., p. 66); e o de (b) "fruição": “Trata-se do aproveitamento satisfatório e prazeroso de obras literárias, musicais ou artísticas, de modo geral - bens culturais construídos pelas diferentes linguagens -, depreendendo delas seu valor estético. Apreender a representação simbólica das experiências humanas resulta da fruição de bens culturais" (Ibid., p. 67).

Nas Orientações curriculares para o ensino médio surgidas quatro anos mais tarde, expressa-se a preocupação de que o termo "fruição", tal como empregado no trecho acima, pudesse ser confundido "com divertimento, com atividade lúdica simplesmente” (BRASIL, 2006, p. 59), julgando-se por bem, então, especificar: "Quanto mais profundamente o leitor se apropriar do texto e a ele se entregar, mais rica será a experiência estética, isto é, quanto mais letrado literariamente o leitor, mais crítico, autônomo e humanizado será” (Ibid., p. 6o). Desse comentário é possível depreender a compreensão, que o preside, da literatura como "meio de educação da sensibilidade” (Ibid., p. 52), em plena consonância com um ensino literário que visa sobretudo ao cumprimento do "Inciso III" dos objetivos estabelecidos para o ensino médio pela "Lei de Diretrizes e Bases da Educação Nacional no 9394/96", a saber: "aprimoramento do educando como pessoa humana, incluindo a formação ética e o desenvolvimento da autonomia intelectual e do pensamento crítico" (Ibid., p. 53).

Conceber, assim, o ensino literário em termos de um processo de Bildung no qual "a fruição de bens culturais", isto é, do "patrimônio representativo da cultura" tal como recuperável "pelo estudo do texto literário", resulta na apreensão, pelo aluno-leitor, da "representação simbólica das experiências humanas", o que, espera-se, o tornará um leitor "mais crítico, autônomo e humanizado" - isso, bem entendido, não impede que o professor venha a ser questionado acerca daquilo mesmo que toma como texto literário a ser estudado, do valor estético que atribui a esse texto, como nas situações de sala de aula apresentadas pelo documento de 2000: "Machado de Assis é literatura, Paulo Coelho não. Por quê? As explicações não fazem sentido para os alunos" (BRASIL, 2000, p. 16); ou: 
Solicitamos que alunos separassem de um bloco de textos, que iam desde poemas de Pessoa e Drummond até contas de telefone e cartas de banco, textos literários e nãoliterários, de acordo como são definidos. Um dos grupos não fez qualquer separação. Questionados, os alunos responderam: "Todos são não-literários, porque servem apenas para fazer exercícios na escola". E Drummond? Responderam: "Drummond é literato, porque vocês afirmam que é, eu não concordo. Acho ele um chato. Por que Zé Ramalho não é literatura? Ambos são poetas, não é verdade?" (Ibid., p. 16).

Diante de tais questionamentos, o professor pode, de fato, querer fazer valer sua crença arraigada - a exemplo do que faz Beatriz Sarlo em relação a Sebald - de que determinados textos - neste caso: os de Machado e Drummond -, logram preservar seu "potencial crítico" em face da mercantilização da cultura pela indústria cultural globalizada, ao passo que outros não - neste caso: os de Paulo Coelho e Zé Ramalho -, e de que apenas aos primeiros deve ser reservado o estatuto de "literatura"; o professor pode, ainda, por esse mesmo e/ou outros motivos, querer reservar aos autores do primeiro tipo de texto a distinção de verdadeiramente representativos da literatura nacional, vetando-a aos autores do segundo tipo de texto. Numa perspectiva oposta, contudo, o professor poderia consentir com a afirmação de que basta "ser poeta", isto é, escrever textos que sejam reconhecidos como “poemas”, para poder ser considerado "literato", ou de que não é factível negar nem a literariedade nem a brasilidade da obra de Paulo Coelho - que já há uma década, aliás, é membro eleito da Academia Brasileira de Letras, fundada, entre outros, pelo velho Machado! -, de que a literatura, enfim, é um campo, a rigor, indelimitável por estritos critérios estético-culturais e/ ou de nacionalidade, seu ensino devendo reger-se pela máxima pluralidade e diversidade possíveis, algo que pareceria em consonância, aliás, com certas "competências [que] deverão ser desenvolvidas no processo de ensino-aprendizagem, ao longo do ensino médio" (Ibid., p. 6), a saber: "Respeitar e preservar as diferentes manifestações da linguagem utilizadas por diferentes grupos sociais, em suas esferas de socialização; usufruir do patrimônio nacional e internacional, com suas diferentes visões de mundo" (Ibid., p. 9); e ainda: "Contextualizar e comparar esse patrimônio, respeitando as visões de mundo nele implícitas” (BRASIL, 2002, p. 69).

Apoiando-se, a certa altura, nas reflexões de Lígia Chiappini acerca dos rumos do ensino literário na contemporaneidade, ${ }^{4}$ as Orientações de 2006 apresentam nos seguintes termos as duas posições contrárias acima indicadas: de um lado, "o professor que só trabalha com autores indiscutivelmente canônicos, como Machado de Assis, por exemplo,

${ }^{4}$ CHIAPPINI, Lígia. Reinvenção da catedral: língua, literatura, comunicação, novas tecnologias, políticas de ensino. São Paulo: Cortez, 2005. 
utilizando-se de textos críticos também consagrados: caso do professor considerado autoritário, conservador, que aprendeu assim e assim devolve ao aluno"; de outro lado, "o professor que lança mão de todo e qualquer texto, de Fernando Pessoa a raps, passando pelos textos típicos da cultura de massa: caso do professor que se considera libertário (por desconstruir o cânone) e democrático (por deselitizar o produto cultural)" (BRASIL, 2006, p. 56). Sobre isso, indaga-se, então:

\begin{abstract}
se existe o professor "conservador" que ignora outras formas de manifestação artística, não haveria, de outro lado, na atitude "democrática”, e provavelmente cheia de boas intenções, um certo desrespeito às manifestações populares, sendo condescendente, paternalista, populista, [...] não haveria demasiada tolerância aos produtos ditos "culturais", mas que visam somente ao mercado? Se vista assim, essa atitude não seria libertária ou democrática, mas permissiva (Ibid., p. 56).
\end{abstract}

A um conservadorismo estético viria contrapor-se, assim, bem entendido, uma permissividade multicultural. Quaisquer que possam ser os argumentos a favor e contra cada uma das duas posturas, o fato é que ambas impossibilitam, na base, cada qual à sua maneira, o desenvolvimento em sala de aula de uma das "competências" previstas pelo documento de 2002 para o aluno do ensino médio, a saber: "Emitir juízos críticos sobre manifestações culturais", competência sobre a qual se diz: "A formulação de opiniões sustentadas por argumentos é condição para construir um posicionamento sobre manifestações culturais que se sucedem no tempo e no espaço"; e ainda: "Não basta considerar algo como belo ou não; é preciso saber de que premissas se parte para valorizar determinados procedimentos de ordem estética, sem perder de vista que tais valores são variáveis no tempo e no espaço" (BRASIL, 2002, p. 65).

Ora, essa emissão-dejuízos-argumentados-de-valor-acerca-de-manifestaçõesculturais não é outra coisa senão a crítica - a atividade que tanto um Northrop Frye quanto um Antonio Candido identificaram como a essência do ensino literário: o que se ensina, a rigor, nas escolas, não é a própria literatura, mas a crítica literária (FRYE, 1971, p. 11), o chamado ensino da literatura devendo ser considerado, na verdade, um aspecto da crítica (CANDIDO, 1988, p. 9). Se o conservadorismo estético impossibilita o desenvolvimento do juízo crítico em sala de aula à medida que impõe doutrinariamente ao aluno o produto de uma decisão crítica já tomada: um "valor estético" a ser meramente internalizado e reproduzido pelo aluno, a permissividade multicultural impossibilita o desenvolvimento do juízo crítico em sala de aula à medida que solapa de antemão a factibilidade de todo e qualquer "valor estético", eliminando, assim, o espaço para a tomada de decisão crítica por parte do aluno. 
Daí a urgência do desafio contundentemente lançado pelo documento de 2002: "Ou bem nos empenhamos na construção de competências que permitam ao aluno emitir juízo crítico sobre os bens culturais ou continuamos a nos conformar com o dogmatismo, cristalizado no magister dixit" (BRASIL, 2002, p. 51). Esta, pois, em suma, a tarefa máxima de que deveria se ocupar uma pedagogia literária na contemporaneidade.

\section{REFERÊNCIAS BIBLIOGRÁFICAS}

BRASIL. Orientações curriculares para o ensino médio: Linguagens, códigos e suas tecnologias. Brasília: Ministério da Educação, 2006.

BRASIL. Parâmetros Curriculares Nacionais: Língua Portuguesa. (Ensino de $1^{\underline{a}}$ a $4^{\underline{a}}$ série). Brasília: Ministério da Educação, 1997.

BRASIL. Parâmetros Curriculares Nacionais: Língua Portuguesa. (Ensino de $5^{\mathfrak{a}}$ a $8^{\underline{a}}$ série). Brasília: Ministério da Educação, 1998.

BRASIL. Parâmetros Curriculares Nacionais: Linguagens, códigos e suas tecnologias. (Ensino Médio). Brasília: Ministério da Educação, 2000.

BRASIL. PCN+Ensino Médio: Orientações educacionais complementares aos Parâmetros Curriculares Nacionais: Linguagens, códigos e suas tecnologias. Brasília: Ministério da Educação, 2002.

CANDIDO, Antonio. O método crítico de Sílvio Romero. São Paulo: EdUSP, 1988 [1945].

EAGLETON, Terry. The idea of culture. Oxford: Blackwell, 2ooo. [Ed. bras.: EAGLETON, Terry. A ideia de cultura. Trad. de Sandra C. Branco. São Paulo: Ed. da UNESP, 2005.]

EAGLETON, Terry. Literary theory: an introduction. 2. ed. Minneapolis: The University of Minnesota Press, 1996. [Ed. bras.: EAGLETON, Terry. Teoria da literatura: uma introdução. Trad. de Waltensir Dutra. 4. ed. São Paulo: Martins Fontes, 2001.]

FRYE, Northrop. Anatomy of criticism: four essays. Princeton (NJ): Princeton University Press, 1971 [1957]. [Ed. bras.: FRYE, Northrop. Anatomia da crítica: quatro ensaios. Trad. de Péricles Eugênio da Silva Ramos. São Paulo: Cultrix, 1973.]

MOREIRAS, Alberto. The exhaustion of difference: the politics of Latin American Cultural Studies. Durhan/London: Duke University Press, 2001. [Ed. bras.: MOREIRAS, Alberto. A exaustão da diferença: a política dos estudos culturais latino-americanos. Trad. de Eliana L. de Lima Reis e Gláucia R. Gonçalves. Belo Horizonte: Ed. UFMG, 2001.]

RAMA, Angel. La ciudad letrada. Hanover (New Hampshire): Ediciones del Norte, 1984. [Ed. bras.: RAMA, Angel. A cidade das letras. Trad. de Emir Sader. São Paulo: Brasiliense, 1985.] 


$$
420 \text { - Remate de Males } 34.2
$$

READINGS, Bill. The university in ruins. Cambridge (MA)/London: Harvard University Press, 1996. [Ed. port.: READINGS, Bill. A universidade em ruínas. Trad. de Joana Frazão. Coimbra: Angelus Novus, 2003.]

SARLO, Beatriz. A literatura na esfera pública. Trad. de Adriana S. Pagano. In: MARQUES, Reinaldo; VILELA, Lúcia Helena (Org.). Valores: arte, mercado, política. Belo Horizonte: Ed. UFMG, 2002. p. 37-55.

SILVEIRA, Rosa Maria Hessel. Apresentação. In: SILVEIRA, Rosa Maria Hessel (Org.). Cultura, poder e educação: um debate sobre estudos culturais em educação. Canoas (RS): Ed. da ULBRA, 2005. p. 5-9. 